\title{
A New Validated Potentiometric Method for Sulfite Assay in Beverages Using Cobalt(II) Phthalocyanine as a Sensory Recognition Element
}

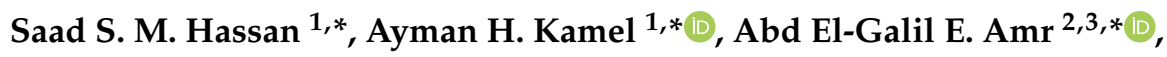 \\ Hisham S. M. Abd-Rabboh ${ }^{4}\left(\mathbb{D}\right.$, Mohamed A. Al-Omar $^{2}\left(\mathbb{D}\right.$ and Elsayed A. Elsayed ${ }^{5,6}(\mathbb{C}$ \\ 1 Department of Chemistry, Faculty of Science, Ain Shams University, Cairo 11566, Egypt \\ 2 Pharmaceutical Chemistry Department, College of Pharmacy, King Saud University, \\ Riyadh 11451, Saudi Arabia; malomar1@ksu.edu.sa \\ 3 Applied Organic Chemistry Department, National Research Center, Dokki 12622, Giza, Egypt \\ 4 Chemistry Department, Faculty of Science, King Khalid University, P.O. Box 9004, Abha 61413, Saudi Arabia; \\ hasalah@hotmail.com \\ 5 Zoology Department, Faculty of Science, King Saud University, Riyadh 11451, Saudi Arabia; \\ eaelsayed@ksu.edu.sa \\ 6 Chemistry of Natural and Microbial Products Department, National Research Centre, \\ Dokki 12622, Cairo, Egypt \\ * Correspondence: saadsmhassan@sci.asu.edu.eg (S.S.M.H.); ahkamel76@sci.asu.edu.eg (A.H.K.); \\ aamr@ksu.edu.sa (A.E.-G.E.A.); Tel.: +20-1222162766 (S.S.M.H.); +20-1000743328 (A.H.K.); \\ $+966-565-148-750$ (A.E.-G.E.A.)
}

Received: 16 June 2020; Accepted: 2 July 2020; Published: 6 July 2020

\begin{abstract}
A simple potentiometric sensor is described for accurate, precise, and rapid determination of sulfite additives in beverages. The sensor is based on the use of cobalt phthalocyanine as a recognition material, dispersed in a plasticized poly(vinyl chloride) matrix membrane. o-Nitrophenyl octyl ether (o-NPOE) as a membrane solvent and tri-dodecylmethyl- ammonium chloride (TDMAC) as ion discriminators are used as membrane additives. Under the optimized conditions, sulfite ion is accurately and precisely measured under batch and flow injection modes of analysis. The sensor exhibits fast and linear response for $1.0 \times 10^{-2}-1.0 \times 10^{-6} \mathrm{M}(800-0.08 \mu \mathrm{g} / \mathrm{mL})$ and $1.0 \times 10^{-1}-5.0 \times 10^{-5} \mathrm{M}(8000-4 \mu \mathrm{g} / \mathrm{mL})$ sulfite with Nernstian slopes of $-27.4 \pm 0.3$ and $-23.7 \pm 0.6 \mathrm{mV} /$ concentration decade under static and hydrodynamic modes of operation, respectively. Results in good agreement with the standard iodometric method are obtained.Validation of the assay method is examined in details including precision, accuracy, bias, trueness, repeatability, reproducibility, and uncertainty and good performance characteristics of the method are obtained. The sensor response is stable over the $\mathrm{pH}$ range of 5 to 7 without any significant interference from most common anions. The advantages offered by the proposed sensor (i.e., wide range of assay, high accuracy and precision, low detection limit, reasonable selectivity, long term response stability, fast response, and long life span and absence of any sample pretreatment steps) suggest its use in the quality control/quality assurance routine tests in beverages industries, toxicological laboratories and by inspection authorities.
\end{abstract}

Keywords: sulfite measurements; potentiometry; sulfite sensor; beverages; flow injection analysis; method validation

\section{Introduction}

Sulfite ions have been widely used for centuries as preservative for food, beverages, and pharmaceutical products [1,2]. It is added to prevent oxidation, enzymatic and non-enzymatic 
browning, and bacterial growth [3]. As sulfite is considered as a hazard to human health, especially for persons with sulfite oxidase deficiency disease, the use of sulfite in foodstuff has to be controlled. The Food and Drug Administration, USFDA, has established $10 \mathrm{ppm}$ as the threshold for declaration of sulfite in the labeling of food, non-alcoholic beverages, and wine products [4,5]. Therefore, the development of a sensitive, selective, fast, and cost effective method for the determination of sulfite is very important and highly demanded for food quality control and quality assurance.

Previously described analytical methods for the determination of sulfite include spectrophotometry based on reactions with formaldehyde-pararosaniline [6], methyl red [7], and diaquacobyrinic acid heptamethyl ester (diaquacobester, DACbs) [8]. Spectrofluorimetric methods for the determination of sulfite include the use of tetra-substituted amino aluminum phthalocyanine [9] rhodamine B hydrazide [10], and N-(9-acridinyl) maleimide (NAM) [11]. Indirect methods for spectrophotometric quantification of sulfite in beverageshave been also suggested [12,13]. Chemiluminescence (CL) measurements have been described using riboflavin phosphate or brilliant sulfaflavine [14], luminol [15], and riboflavin phosphate [16]. Phosphorimetric assay of sulfite has been described using Pt(II) coproporphyrin/bovine serum albumin [17].

Chromatographic methods for sulfite analysis have been widely used including ion chromatography [18], gas chromatography [19], liquid chromatography [20,21], zone electrophoresis [22] and ion exclusion chromatography [23]. Enzymatic assays using sulfite oxidase enzyme, supported on an oxygen sensor, and following the decrease in dissolved oxygen concentration $[4,24,25]$ with an $\mathrm{H}_{2} \mathrm{O}_{2}$ sensor or Clark-type oxygen electrode. An amperometric sulfite oxidase/ cytochrome c-based sensor has been also used [26]. However, most of the previously described methods and techniques are not selective, need tedious sample pretreatment steps, are time consuming, and are not sensitive enough to determine low concentrations of sulfite in real food samples.

Electrochemical techniques including amperometry and voltammetry have been described [27-31]. With the hallmarks of high sensitivity, selectivity, easy operation, and a variety of probes available, potentiometric sensors are a good alternative to sulfite detection. Ion-selective electrodes (ISEs) that contain selectivity carriers (i.e., ionophores) have been used widely to detect different types of ions in medical, environmental, and industrial analyzes [32-37]. On the other hand, little is known about the use of potentiometric sensors for sulfite quantitation. Potentiometric sulfite sensors with polymeric membranes incorporating mercury(II) diethydithiocarbamate [38], guanidinium ionophore [39], and solid-state membrane sensor based on titanium phosphate epoxy have been developed and used for manual and flow injection analysis of sulfite [40]. On the other hand, no commercial sensors are available in the market, so far, for sulfite quantification.

In this contribution, a simple, fast, and sensitive potentiometric sensor for sulfite determination under static and hydrodynamic modes of operation based on the use of cobalt phthalocyanine as an efficient sulfite recognition sensing reagent is described. This macrocyclic reagent is chemically stable, environmentally friendly, non-toxic, exhibits physically interesting electrochemical properties for selective sulfite sensing. A PVC membrane sensor based on cobalt phthalocyanine is developed, characterized and used under static and hydrodynamic modes of operation for sulfite measurements in beverages. The sensor is suitable for quality control/quality assurance in beverage industry as it offers low detection limit, a wide linear response range, good selectivity, high accuracy, long term stability, and fast response time with a low fabrication cost.

\section{Results and Discussions}

Cobalt phthalocyanine ( $\mathrm{CoPc})$, a $p$-type organic semiconductor with an $18 \pi$-electron system, was examined as a potentiometric recognition ionophore for selective and sensitive potentiometric determination of sulfite ion. A preliminary investigation was conducted by testing the interaction of sulfite ion with a solution of Co(II)-phthalocyanine. Cobalt phthalocyanine was completely insoluble in aqueous solutions but readily dissolves in dimethyl sulfoxide (DMSO), tetrahydrofuran (THF), and dioxane solvents, displaying absorption spectrum in the visible region with two maxima. Solutions 
of cobalt phthalocyanine in tetrahydrofuran and dioxane were unstable because the absorbance at these two wavelengths rapidly decreased with time. Dimethyl sulfoxide (DMSO) showed good dissolution properties and long-term color stability of cobalt phthalocyanine. The absorption spectrum of Co (II)-phthalocyanine in DMSO solution displayed two absorption peaks at 620 and $666 \mathrm{~nm}$ (Figure 1).

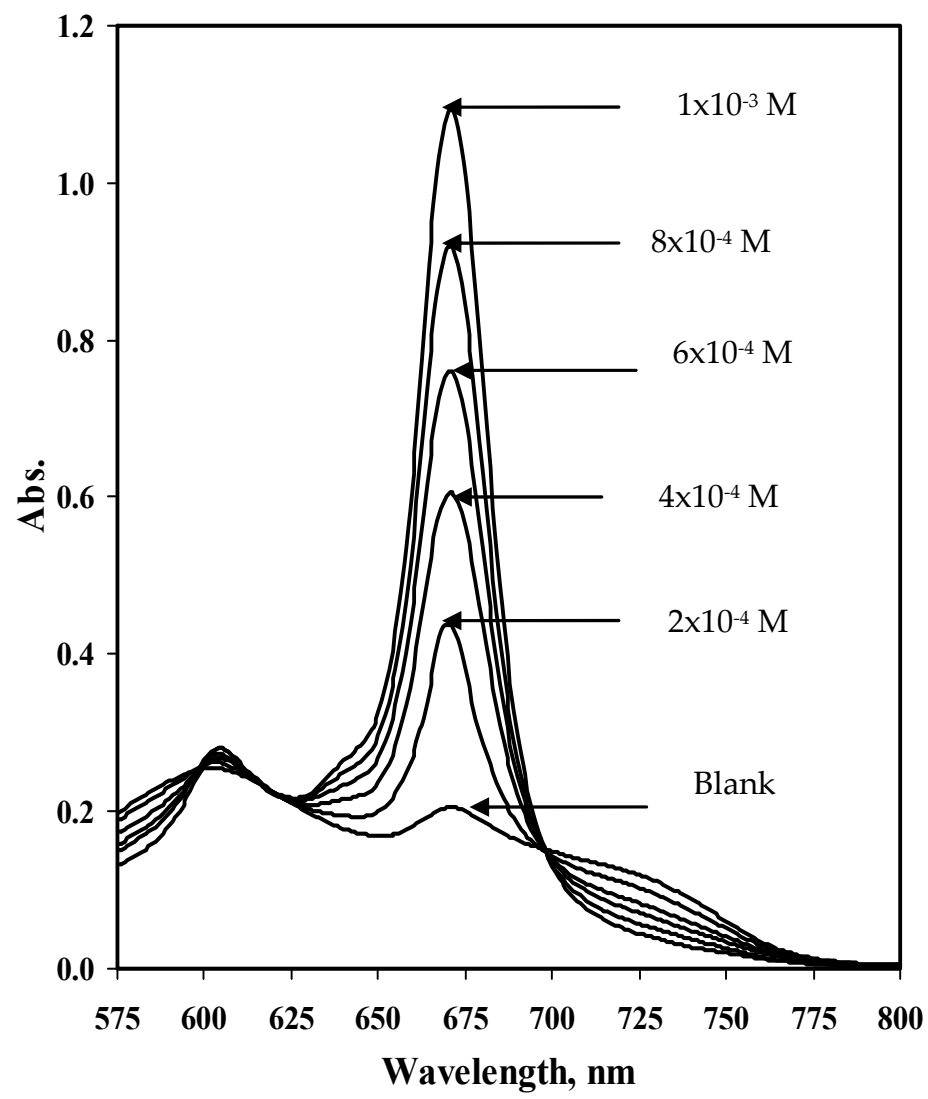

Figure 1. Absorption spectra of sulfite calibrants in the range of $2 \times 10^{-4}$ to $1 \times 10^{-3} \mathrm{M}$ after the addition of $1 \mathrm{~mL}$ of $0.1 \mathrm{mg} / \mathrm{mL}$ CoPC in DMSO.

Addition of sulfite ions to the Co (II)-complex solution caused a slight decrease in the peak intensity at $620 \mathrm{~nm}$ and a slight bathochromic shift of the $666 \mathrm{~nm}$ peak to $670 \mathrm{~nm}$. The last peak was sensitive and linearly increased in absorbance with the increase of sulfite concentration over the range 16 to $80 \mu \mathrm{g} / \mathrm{mL}$, probably due to ligation of the sulfite ion to one of the axial position on the Co(II)-complex with subsequent oxidation of $\mathrm{Co}$ (II) to $\mathrm{Co}(\mathrm{III})$, Figure 2. Although a $\mathrm{Co}(\mathrm{II})$-phthalocyanine was used to prepare these ISE membranes, the response mechanism can be explained as a charged-carrier mechanism, which was speculated to be due to oxidation of the metal center to $\mathrm{Co}(\mathrm{III})$.

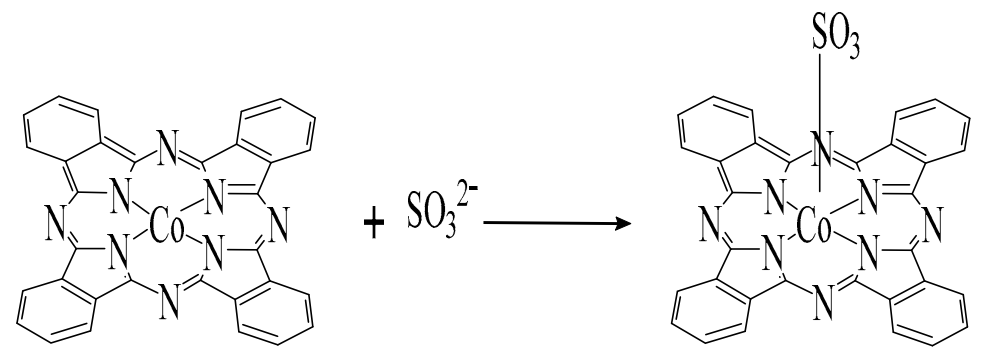

Figure 2. Ligation of sulfite ion to Co(II)-phthalocyanine complex. 
It has been reported that sulfite ion coordinates to iron and cobalt phthalocyanines during the electro catalytic oxidation of sulfur dioxide by these complexes [41]. Ligation of sulfite to Co(II)-tetrasulfophthalocyanine in organic solvents has been also demonstrated [42].

Common interfering anions (e.g., nitrite, nitrate, chloride, fluoride, azide, sulfate, phosphate, acetate, and thiocyanate ions) had no significant effect on the absorption spectrum compared to the blank. Addition of 50-100-fold excess of these ions did not contribute by more than $2 \%$ error. These data provide a clear evidence for the reasonable recognition characteristics and good sensitivity and selectivity of the proposed reagent towards sulfite ion over the most common interfering anions.

\subsection{Potentiometric Recognition of Sulfite}

A polymeric membrane potentiometric sensor consisting of cobalt phthalocyanine as an ionophore, dioctylphthalate (DOP) or ortho-nitrophenyloctylether (o-NPOE) as a plasticizer, and PVC as polymeric matrix in the optimum ratio of (1.0:69:30), respectively, was prepared and tested as a sulfite ion sensor. Effects of the membrane plasticizer, background solution, and membrane additives were tested. A membrane incorporating DOP plasticizer (low dielectric constant, $\varepsilon=7$ ) was first tested. A calibration graph made in $10^{-3} \mathrm{M} \mathrm{NaCl}$ background solution as an ionic strength adjustor (ISA) showed a linear potential response over the concentration range of $4.5 \times 10^{-5}$ to $1.1 \times 10^{-3} \mathrm{M}$ sulfite $(3.6-88 \mu \mathrm{g} / \mathrm{mL})$ with a Nernstian slope of $-25.5 \pm 0.2 \mathrm{mV} /$ decade and a detection limit of $2.0 \times 10^{-5} \mathrm{M}$ $(1.6 \mu \mathrm{g} / \mathrm{mL})$ (Figure 3). Calibration parameters in pure aqueous media were inferior to those obtained in the presence sodium chloride background.

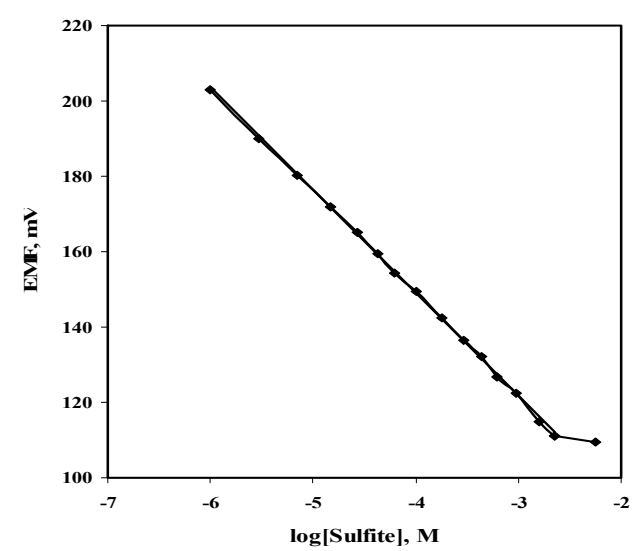

Figure 3. Calibration plot of sulfite ion using [CoPC/TDMA $\left.{ }^{+} / o-\mathrm{NPOE}\right] \mathrm{PVC}$ membrane-based sulfite sensor in a mixture of $10^{-2} \mathrm{M}$ acetate buffer of $\mathrm{pH} 5$ and $10^{-3} \mathrm{M} \mathrm{NaCl}$ as a background solution.

The effect of incorporating aniondiscriminator as a membrane additive, such as tridodecylmethylammonium chloride (TDMAC) in the membrane phase of the sensor slightly improved the performance characteristics of the sensor (linear range, slope and detection limit of the calibration plot). The calibration slope became $-26.8 \mathrm{mV} /$ decade and the limit of detection reached $1.4 \times 10^{-5}$. Membranes containing $o$-nitrophenyloctyl ether plasticizer, $o$-NPOE (high dielectric constant, $\varepsilon=23$ ) were next examined. A typical calibration curve for the sulfite sensor incorporating CoPC/TDMA ${ }^{+} / 0$-NPOE in a background of $10^{-2} \mathrm{M}$ acetate buffer of $\mathrm{pH} 5$, and $10^{-3} \mathrm{M} \mathrm{NaCl}$ is shown in Figure 3. The linear range increased to cover the range of $1.0 \times 10^{-6}$ to $2.2 \times 10^{-3} \mathrm{M}(0.08-176 \mu \mathrm{g} / \mathrm{mL})$ with a better detection limit of $1.0 \times 10^{-6} \mathrm{M}(0.08 \mu \mathrm{g} / \mathrm{mL})$ and a calibration slope of $-27.4 \mathrm{mV} /$ decade of sulfite concentration. Table 1 summarizes the different performance characteristics of the sulfite sensor under the optimized conditions. All subsequent experiments were made with this sensor.

Table 1 Performance characteristics of the [CoPC/TDMA $\left.{ }^{+} / \mathrm{o}-\mathrm{NPOE}\right]$ sulfite PVC membrane sensor in $10^{-2} \mathrm{M}$ acetate buffer and $10^{-3} \mathrm{M} \mathrm{NaCl}(\mathrm{pH}$ ) under batch and FIA modes of operation. 
Table 1. Performance characteristics of the [CoPC/TDMA $\left.{ }^{+} / \mathrm{o}-\mathrm{NPOE}\right]$ sulfite PVC membrane sensor in $10^{-2} \mathrm{M}$ acetate buffer and $10^{-3} \mathrm{M} \mathrm{NaCl}(\mathrm{pH}$ ) under batch and FIA modes of operation.

\begin{tabular}{|c|c|c|}
\hline \multirow{2}{*}{ Parameter } & \multicolumn{2}{|c|}{ Value } \\
\hline & Batch & FIA \\
\hline Calibration range, $M$ & $1.1 \pm 0.1 \times 10^{-6}-2.2 \pm 0.1 \times 10^{-3}$ & $5.0 \pm 0.5 \times 10^{-5}-1.0 \pm 2 \times 10^{-1}$ \\
\hline Slope, $m V / \log \left[\mathrm{SO}_{3}\right]$ & $-27.4 \pm 0.3$ & $-23.7 \pm 0.6$ \\
\hline Low detection limit, $M$ & $1.1 \pm 0.1 \times 10^{-6}$ & $1.1 \pm 0.3 \times 10^{-5}$ \\
\hline Correlation coefficient, $r^{2}$ & 0.9994 & 0.9965 \\
\hline Response time for $10^{-5} \mathrm{M}, s$ & $5 \pm 2$ & $50 \pm 5$ \\
\hline Recovery time for $10^{-5} \mathrm{M}, \mathrm{s}$ & $10 \pm 3$ & $55 \pm 5$ \\
\hline Working acidity range, $p H$ & $5-7$ & $5-7$ \\
\hline Accuracy, \% & $98.1 \pm 0.7$ & $97.3 \pm 1.1$ \\
\hline Trueness, $\%$ & $98.0 \pm 0.8$ & $97.1 \pm 1.2$ \\
\hline Bias, $\%$ & $2.0 \pm 0.2$ & $3.2 \pm 0.8$ \\
\hline Within-day Repeatability, $C V_{w} \%$ & $0.7 \pm 0.2$ & $1.1 \pm 0.4$ \\
\hline Between days- variation, $C V_{b} \%$ & $0.9 \pm 0.1$ & $1.3 \pm 0.5$ \\
\hline Relative Standard deviation, $\%$ & $0.9 \pm 0.1$ & $1.2 \pm 0.2$ \\
\hline Precision, $\%$ & $0.7 \pm 0.2$ & $0.8 \pm 0.4$ \\
\hline
\end{tabular}

\subsection{Effect of $p H$}

The effect of $\mathrm{pH}$ on the potentiometric response of the sulfite sensor was evaluated by changing the $\mathrm{pH}$ of $1.0 \times 10^{-3} \mathrm{M} \mathrm{SO}_{3}^{2-}$ solution in a $1.0 \times 10^{-3} \mathrm{M} \mathrm{NaCl}$ background from $\mathrm{pH} 3$ to 11 by adding aliquots of concentrated sodium hydroxide and/or acetic acid solutions. The corresponding $\mathrm{mV}$ readings at each $\mathrm{pH}$ value were recorded after each addition. Figure 4 shows an independence of the sensor's response for sulfite ions over the $\mathrm{pH}$ range 5 to 7 . Above and below this range, the sensor potential was sharply decreased. At high $\mathrm{pH}$ values of $>8$, the sensor responded to $\mathrm{OH}^{-}$ion, while at low $\mathrm{pH}$ values of $<3$, the sensor responded to the monovalent $\mathrm{HSO}_{3}{ }^{-}\left(p K a_{1}=1.89\right.$ and $p K a_{2}=7.21$ at $25^{\circ} \mathrm{C}$ ). A $10^{-2} \mathrm{M}$ acetate buffer solution of $\mathrm{pH} 5$, containing $10^{-3} \mathrm{M} \mathrm{NaCl}$ was used as a background solution and used for all subsequent measurements.

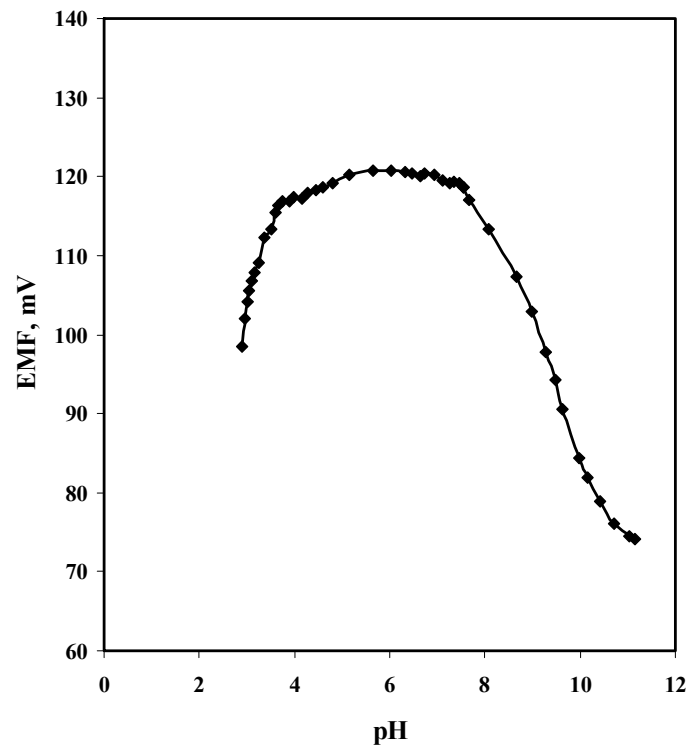

Figure 4. Effect of $\mathrm{pH}$ on the potentiometric response of [CoPC/TDMA $\left.{ }^{+} / 0-\mathrm{NPOE}\right] \mathrm{PVC}$ membrane based sulfite sensor using $10^{-3} \mathrm{M}$ sulfite solution. 


\subsection{Potentiometric Selectivity of CoPC/TDMAC-based Sulfite Sensor}

The potentiometric selectivity coefficients ( $K^{\text {Pot }}$ Sulfite, $)$ of the sulfite sensor were measured according to the IUPAC guidelines using the fixed interfering method (FIM) [43]. In this method, $1 \mathrm{~mL}$ of $1.0 \times 10^{-2} \mathrm{M}$ of the interfering ion solution was added to $9.0 \mathrm{~mL}$ of a $1: 1 \mathrm{mix}$ of $1.0 \times 10^{-3} \mathrm{M} \mathrm{NaCl}$ and $1.0 \times 10^{-3} \mathrm{M}$ acetate buffer of $\mathrm{pH} 5$ in presence of fixed concentration of sulfite ion $\left(10^{-3} \mathrm{M}\right)$. Equation (1) was used for calculation,

$$
\log K^{p o t}{ }_{\mathrm{ij}}=\log a_{i}-\log a_{j}^{Z i / Z j}
$$

where $a_{i}$ and $a_{j}$ are the activities of the primary and interfering ions, respectively, and $z_{i}$ and $z_{j}$ are their respective charges.

The obtained results revealed that the CoPC/TDMA $+/ 0-\mathrm{NPOE}-$ based sulfite sensor exhibited reasonable selectivity towards sulfite ion over most common ions, which was in a good agreement with data obtained by the spectrophotometric measurements. The selectivity coefficients for nitrate, nitrite, chloride, fluoride, azide, sulfate, phosphate, and acetate ranged from $10^{-2}$ to $10^{-3}$. Thiocyanate ion, however, significantly interferes but it is fortunate that thiocyanate ion rarely coexists with sulfite in real beverages.

\subsection{Potentiometric Batch and Flow Injection Analysis (FIA) of Sulfite}

Replicate measurements of 1.0 and $10.0 \mu \mathrm{g} / \mathrm{mL}$ internal quality control sulfite sample (IQS) under batch mode of operation and calculation of the student's $(t)$ value at 95\% confidence level were made. No statistical difference was detected between the calculated and the theoretical values.

A flow injection analysis (FIA) of different sulfite calibration solutions using a CoPC/TDMA ${ }^{+}$ based tubular detector was made. The calibration data exhibited good linearity over the concentration range $5.0 \times 10^{-5}$ to $1.0 \times 10^{-1} \mathrm{M}$. The detected low sulfite concentration and wide linear range of measurements permitted accurate monitoring of sulfite in a variety of real beverage samples in the drink industries. Typical FIA signals for different sulfite concentrations are shown in Figure 5 . The rate of analysis is 50-60 runs /hour. The technique offers a simple and rapid viable tool for beverage assessment in view of the absence of any commercial sulfite sensor.

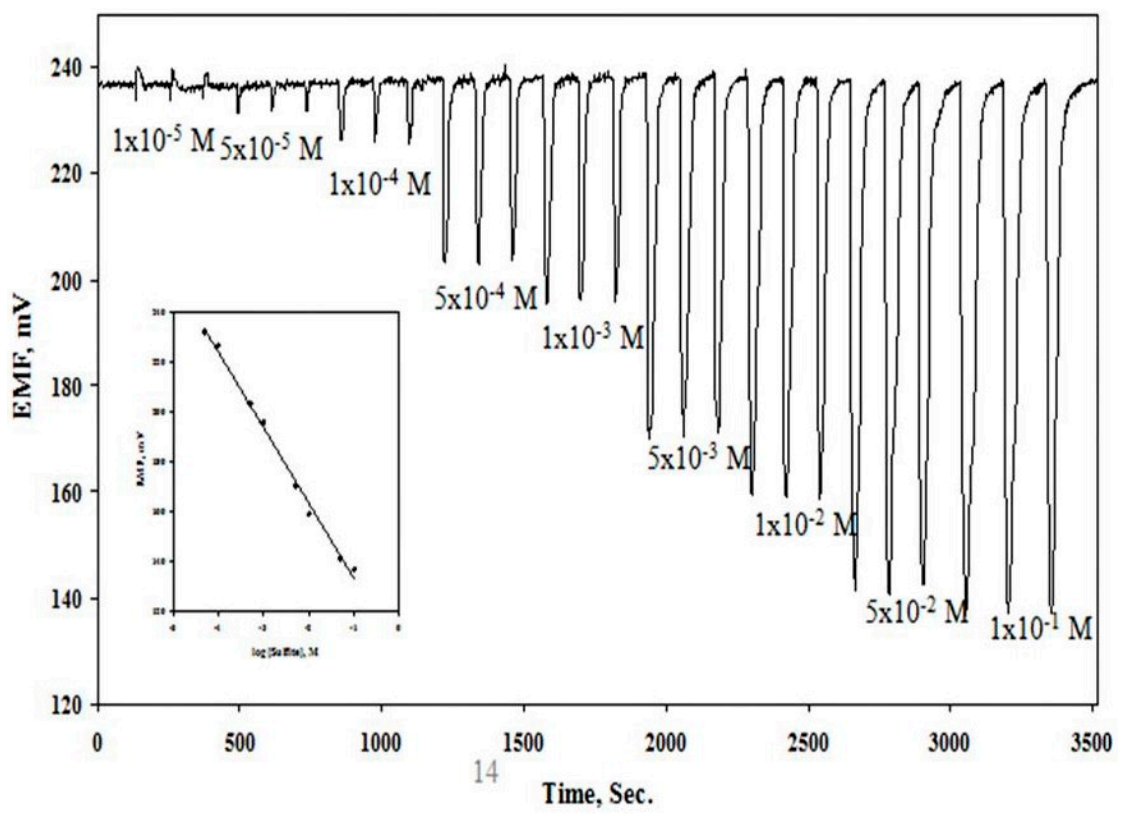

Figure 5. Potentiometric FIA chart for sulfite calibrants using [CoPC/TDMA $\left.{ }^{+} / 0-\mathrm{NPOE}\right] \mathrm{PVC}$ membrane. 


\subsection{Method Validation}

Validation of the proposed potentiometric method was performed, using the quality control/quality assurance standards and guidelines [44,45], to verify that the performance characteristics of the method are suitable for sulfite measurement in beverage industry and to provide documented evidence that thedeveloped proceduredoes what it is intended to do. Six batches (six determinations each) covering the concentration range of 1.0 to $300.0 \mu \mathrm{g} / \mathrm{mL}$ sulfite were used for evaluation of the assay range, accuracy, trueness, bias, precision, lower limit of detection, standard deviation, within-day repeatability $\left(C V_{w}\right)$, between-days-variability $\left(C V_{b}\right)$, ruggedness (robustness), and uncertainty.

\subsubsection{Data Precision and Accuracy}

Repeated measurements of an internal quality control sulfite samples containing 1.0, 10.0, 50.0, $100.0,200.0$, and $300.0 \mu \mathrm{g} / \mathrm{mL}$ sulfite $(n=6$, each) showed relative standard deviations $(R S D)$ in the range $\pm 0.9 \pm 0.1-1.2 \pm 0.2 \%$. Theaverage of sulfite results $(X)$ and the standard deviation $(S)$ were calculated to evaluate the method precision using Equation (2),

$$
\text { Precision, } \%=(S / X) \times 100
$$

where $X$ is the mean of test results obtained for the sulfite reference standard sample and $S$ is the standard deviation of $X$. Absolute uncertainty is expressed as: $X$ sulfite value \pm precision.

The degree of agreement or the closeness of test results obtained by the proposed sensor with the true (labeled) sulfite value was measured by spiking (adding) of a reference sulfite samples. The accuracy of the assay method across the dynamic range of the analytical procedure was calculated using Equation (3) and found to be $98.1 \pm 0.7-97.3 \pm 1.1 \%$,

$$
\text { Accuracy, } \%=\left[\left(X_{s}-X\right) / X_{a d d}\right] \times 100
$$

where $X_{S}$ is the mean result of the spiked sulfite solution, $X$ is the mean result of un-spiked sulfite samples, and $X_{\text {add }}$ is the amount of added sulfite standard.

\subsubsection{Data Trueness and Bias}

Replicate analyses performed on reference sulfite samples (1.0, 10.0, 50.0, 100.0, 200.0, and $300.0 \mu \mathrm{g} / \mathrm{mL}$ sulfite) were also used to determine method trueness and bias according to Equations (4) and (5), respectively.

$$
\begin{aligned}
& \text { Trueness, } \%=(X / \mu) \times 100 \\
& \text { Bias, } \%=[(X-\mu) / \mu] \times 100
\end{aligned}
$$

where $X$ is the mean of test results obtained for the reference sample and $\mu$ is thetrue value of the reference sample. The mean trueness and bias percentages obtained, ranged between 98.0 $\pm 0.8-97.1 \pm$ $1.2 \%$ and $2.0 \pm 0.2-3.2 \pm 0.8 \%$, respectively.

\subsubsection{Data Repeatability and Reproducibility}

The spread of results when a sulfite sample $(1.0-300.0 \mu \mathrm{g} / \mathrm{mL})$ was measured in the same day and on different days to conform the agreement between results obtained with the sulfite reference sample under different conditions with different sensor assembly and $\mathrm{pH}$ meters at different times. The reproducibility $(R)$ is calculated from the standard deviation data of the results $\left(s_{R}\right)$ (Equation (6)).

$$
R=2.8 \times S_{R}
$$


where $2.8=2 \sqrt{ } 2$ and is derived from the normal or Gaussian distribution; ISO 5725). The data reproducibility within-day and between-days were found to be $0.7 \pm 0.2-1.1 \pm 0.4 \%$ and $0.9 \pm 0.2-1.3 \pm$ $0.5 \%$, respectively.

\subsubsection{Dynamic Measurement Range and Limit of Detection}

The lower limit of sulfite detection (LOD) was calculated according to the IUPAC guidelines [46]. It is equal to the sulfite concentration corresponding to the intersection of the extrapolated linear segment of the calibration graph. The LOD of the method was found to be $1.0 \times 10^{-6} \mathrm{M}$ $(0.08 \mu \mathrm{g} / \mathrm{mL})$ and $1.0 \times 10^{-5} \mathrm{M}(0.8 \mu \mathrm{g} / \mathrm{mL})$ under batch and flow injection analysis, respectively. The sensor displayed linear dynamic range between $1.0 \times 10^{-2}-1.0 \times 10^{-6} \mathrm{M}(800-0.08 \mu \mathrm{g} / \mathrm{mL})$ and between $5.0 \times 10^{-5}-1.0 \times 10^{-1} \mathrm{M}(4-8000 \mu \mathrm{g} / \mathrm{mL})$ with near-Nernstian slopes of $-27.4 \pm 0.3$ and $-23 \pm 0.6 \mathrm{mV} /$ decade with batch and flow injection analysis, respectively. All the results of the validation protocol which support the applicability and suitability of the proposed sensor for accurate routine analysis of sulfite ion in various beverages are shown in Table 1.

\subsubsection{X-bar and R-Charts}

Based on running duplicate measurements for 10 days, control charts ( $X$ and $R$ ) were prepared for monitoring $0.5,5.0,100.0,200.0$, and $300.0 \mu \mathrm{g} / \mathrm{mL}$ sulfite standard solutions. The results were used to construct both $\mathrm{X}$ - and R-control chart. The distribution of measurements and range of the data under investigation indicated that they were in statistical control $[44,45]$.

\subsection{Potentiometric Determination of Sulfite in Beverages}

The levels of sulfite ion in four real beverage samples were potentiometrically measured using

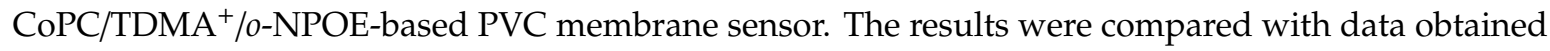
by the standard iodometric method (Table 2). Using direct potentiometry, $1.18-300.0 \mu \mathrm{g} / \mathrm{mL}$ sulfite calibration solutions were measured, each in triplicate, using the sulfite PVC membrane sensor and used for comparison, followed by sample measurements without pretreatment. Potentiometric flow injection analysis, FIA, technique was also used for the analysis. The results obtained under both batch and FIA mode of operation display $98-102 \%$ of the results obtained by the standard iodometric method [47].

Table 2. Determination of sulfite in some beverage samples using potentiometry with the sulfite sensor under batch and FIA modes of operation, spectrophotometry with cobalt phthalocyanine and the standard iodometric method.

\begin{tabular}{|c|c|c|c|c|}
\hline \multirow{3}{*}{ Sample } & \multicolumn{4}{|c|}{ Sulfite, $\mu \mathrm{g} / \mathrm{mL}$} \\
\hline & \multicolumn{2}{|c|}{$\begin{array}{l}\text { Potentiometry, } \\
\text { (Sulfite Sensor) }\end{array}$} & \multirow{2}{*}{$\begin{array}{c}\text { Spectro- } \\
\text { Photometry }\end{array}$} & \multirow{2}{*}{$\begin{array}{c}\text { Iodometry, [47] } \\
\text { (Standard Methods) }\end{array}$} \\
\hline & Batch & FIA & & \\
\hline Beer,(Barq's), USA & $10.9 \pm 0.6$ & $10.4 \pm 0.8$ & - & $11.1 \pm 0.7$ \\
\hline Non-alcoholic Malt Beverage, (Birell), Egypt & $8.1 \pm 0.7$ & $7.9 \pm 0.8$ & - & $8.2 \pm 0.8$ \\
\hline Non-alcoholic Malt Beverage, (Barbican), USA & $9.1 \pm 0.6$ & $9.6 \pm 0.8$ & - & $9.1 \pm 0.8$ \\
\hline White Sparkling Grape Drink, (Carl Yong), Germany & $277.2 \pm 0.6$ & $281.1 \pm 0.9$ & $275.3 \pm 0.7$ & $278.4 \pm 2.3$ \\
\hline White Vinegar, (Heinz), Egypt & $87.0 \pm 0.6$ & $89.2 \pm 1.7$ & $86.9 \pm 1.9$ & $88.3 \pm 2.3$ \\
\hline Sugar Lump, (National Sugar Co.), Egypt & $244.2 \pm 0.6$ & $250.3 \pm 1.3$ & $252.2 \pm 0.8$ & $247.2 \pm 2.6$ \\
\hline
\end{tabular}

The color developed by reaction of sulfite with cobalt phthalocyanine reagent in dimethyl sulfoxide solution was also assessed for sulfite quantization. To $0.5 \mathrm{~mL}$ of a $0.1 \mathrm{mg} / \mathrm{mL}$ solution of CoPC in DMSO $1.0 \mathrm{~mL}$ aliquots of sulfite calibration solutions were added in a quartz cuvette. Sulfite calibration solutions were freshly prepared by diluting 30.0, 60.0, 90.0, 120.0, and $150.0 \mu \mathrm{l}$ of $10^{-2} \mathrm{M}$ stock sulfite solution with de-ionized water to $1 \mathrm{~mL}$. The reagent and sulfite solutions were mixed and the absorbance readings were recorded at $670 \mathrm{~nm}$ as a function of sulfite concentration. Application of the method to real beverage samples containing $>80 \mu \mathrm{g} / \mathrm{mL}$ sulfite, showed results within $98-102 \%$ of that 
obtained by the standard iodometric method [47]. These data revealed that the spectrophotometric method is less sensitive compared with the potentiometric sensors and Beer's law was obeyed over a narrow and relatively higher sulfite concentration range.

\section{Materials and Methods}

\subsection{Equipment}

An Orion double-channel pH/mV meter (Model SA 720, Waltham, MA, USA) equipped with an Orion combination Ross glass $\mathrm{pH}$ electrode (Model 81-02) was used for $\mathrm{pH}$ adjustments. A cobalt phthalocyanine-PVC-based membrane sensor in conjunction with an Orion Ag/AgCl double junction reference electrode (Model 90-02) was used for potentiometric measurements of sulfite. Potentiometric signals were recorded using a home-made high-impedance data acquisition system connected to a PC through the interface ADC 16 (Pico tech., London, UK) and a PicoLog for windows (version 5.07) software (London, UK) Potentiometric measurements were performed at $25 \pm 1{ }^{\circ} \mathrm{C}$.

A laboratory-made potentiometric flow-through tubular cell was equipped with cobalt phthalocyanine-PVC membrane as previously described [48] and incorporated in a single FIA system, with an Omnifit injection valve and a peristaltic pump (Ismatic, MA, USA) cassette junior model. The potentiometric output was measured with the data acquisition setup. A laboratory-made flow-through tubular potentiometric cell, equipped with CoPC-PVC membrane, was fabricated as previously described [48] and used in a single-channel flow injection system. The cell was assembled and incorporated in a flow injection analysis system. The system consisted of an Ismatic cassette pump (Ismatic, MA, USA) an Omnifit injection valve (Omnifit Cambridge, UK) with sample loop of $20 \mu \mathrm{L}$ volume. The flow cell and an Orion 90-02 Ag/AgCl double junction reference electrode were placed in a beaker filled with the electrolyte carrier solution. The carrier stream was propelled by peristaltic pump, through Tygon tubing $(0.8 \mathrm{~mm}$ i.d.) and a mixing coil $(15 \mathrm{~cm})$. The potentiometric signals were monitored with the computerized data acquisition system described above. The FIA system setup is shown in Figure 6. Spectrophotometric measurements were carried out using a computer-controlled UV/Vis double-beam spectrophotometer (Shimadzu, model 1601).

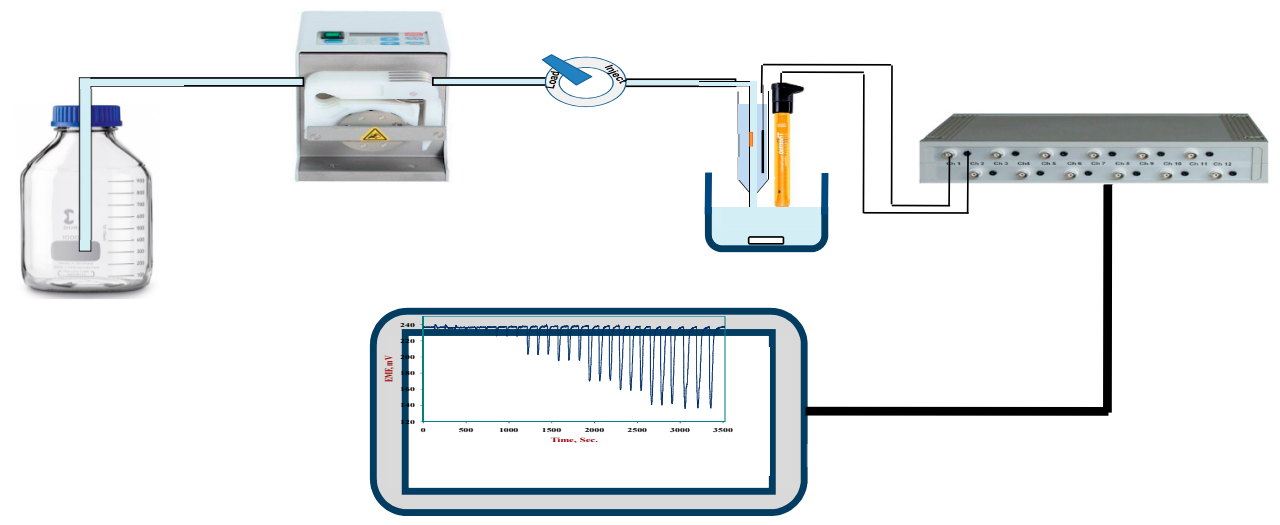

Figure 6. Flow-injection setup: (1) NaCl-acetate buffer reservoir, (2) peristaltic pump, (3) injection valve, (4) cell assembly, (5) double junction reference electrode, (6) high (Z) box, (7) typical flow-transient plot.

\subsection{Materials and Chemicals}

All reagents were prepared from analytical reagent grade chemicals unless otherwise specified and doubly distilled deionized water was used throughout. Cobalt phthalocyanine (CoPC) was obtained from Midcentury (Posen, IL, USA). Tri-dodecylmethyl- ammonium chloride (TDMAC), high molecular weight poly (vinyl chloride) (PVC), M.W. of 100,000, sodium sulfite $\left(\mathrm{Na}_{2} \mathrm{SO}_{3}\right)$, potassium iodate, potassium iodide, sulfamic acid, sulfuric acid, acetic acid, sodium hydroxide, sodium bicarbonate, sodium chloride, dimethyl sulfoxide (DMSO), dioxane, and sodium chloride 
$(\mathrm{NaCl})$ were obtained from Aldrich Chemical Co. (Milwaukee, WI, USA). Tetrahydrofuran (THF), freshly distilled prior to use, $o$-nitrophenyloctyl ether (o-NPOE), and dioctylphthalate (DOP) were purchased from FlukaChemika-Biochemika (Ronkonkoma, NY, USA).

\subsection{Preparation of Sulfite PVC Membrane Sensor}

The polymeric sensing membrane of the sensor was prepared by dissolving $132 \mathrm{mg}$ PVC, $66 \mathrm{mg}$ of plasticizer, $2 \mathrm{mg}$ of CoPC, and $0.4 \mathrm{mg}$ TDMAC in $2 \mathrm{~mL}$ of THF in a glass vial. The membrane cocktail was poured into a glass cup $(22 \mathrm{~mm}$ i.d.) and covered with a piece of filter paper until complete evaporation of THF. A disk of about $6 \mathrm{~mm}$ in diameter was then cut, by the aid of a cork borer, and glued to a piece of Tygon tube ( $5 \mathrm{~mm}$ in inner diameter, $9 \mathrm{~mm}$ in outer diameter, and $2 \mathrm{~cm}$ length) using THF. The Tygon tube was attached to the electrode glass body, and a 1:1 mixture of $10^{-2} \mathrm{M}$ $\mathrm{NaCl}$ solution and $10^{-2} \mathrm{M}$ sodium sulfite solution was used as internal filling solution. $\mathrm{An} \mathrm{Ag} / \mathrm{AgCl}$ electrode was used as internal reference electrode. The potential response of the sensor was measured against an external $\mathrm{Ag} / \mathrm{AgCl}$ double junction reference electrode.

\subsection{Sensor Calibration}

The sulfite sensor in conjunction with $\mathrm{Ag} / \mathrm{AgCl}$ double-junction reference electrode was immersed into a $25 \mathrm{~mL}$ beaker containing $10 \mathrm{~mL}$ of a $1: 1 \mathrm{mix}$ of $1.0 \times 10^{-3} \mathrm{M} \mathrm{NaCl}$ and $1.0 \times 10^{-3} \mathrm{M}$ acetate buffer of $\mathrm{pH}$ 5. Aliquots $\left(1.0 \mathrm{~mL}\right.$ of standard sulfite solutions $\left(1.0 \times 10^{-6}\right.$ to $\left.1.0 \times 10^{-2} \mathrm{M}\right)$ were sequentially added and the potential change after each addition was recorded. A calibration curve was constructed by plotting the potential change against the logarithm of sulfite concentration. The calibration graph was used for subsequent measurement of sulfite levels in real test samples under the same experimental conditions. The sensor was stored in the same solution between measurements.

\subsection{Potentiometric Batch Determination of Sulfite in Beverages}

Sulfite levels in some beverage samples were potentiometrically measured. The standard iodometric method for sulfide assessment was carried in parallel for comparison. The test samples were used without any further treatment. To a $50 \mathrm{~mL}$ beaker containing $10 \mathrm{~mL}$ of a 1:1 mix of $1.0 \times 10^{-3} \mathrm{M} \mathrm{NaCl}$ and $1.0 \times 10^{-3} \mathrm{M}$ acetate buffer of $\mathrm{pH}$, add a $10.0 \mathrm{~mL}$ aliquot of the beverage sample and stir. The working and reference electrodes were immersed in the solution. The potential readings were recorded after stabilization and the concentrations of sulfite in the test samples were calculated using the calibration graph. A blank experiment was carried out under the same conditions without the beverage sample.

\subsection{Potentiometric Flow Injection Analysis (FIA) of Sulfite in Beverages}

A flow stream of the carrier solution $\left(1: 1 \mathrm{mix}\right.$ of $1.0 \times 10^{-3} \mathrm{M} \mathrm{NaCl}$ and $1.0 \times 10^{-3} \mathrm{M}$ acetate buffer of $\mathrm{pH}$ 5) was propelled with a flow rate of $10 \mathrm{~mL} / \mathrm{min}$. The carrier solution was allowed to passes through the flow through-cell by means of a peristaltic pump and Tygon tubing. Successive injections of $20 \mu \mathrm{L}$ aliquots of each sulfite standards $\left(1.0 \times 10^{-1}-1.0 \times 10^{-5} \mathrm{M}\right)$ were made into the

flowing stream. The corresponding signal heights and potential change was measured using a data acquisition system. The $\mathrm{mV}$ vs. logarithm sulfite concentration readings of the sulfite standards were recorded and used for construction of a calibration plot. Beverage solutions were similarly injected (in triplicate) in the flowing stream and the average potential readings of three runs was compared with those of the standard solutions. A blank experiment under the same conditions was carried out.

\subsection{Iodometric Determination of Sulfite in Beverages}

A $100.0 \mathrm{~mL}$ aliquot of the beverage test solution was transferred to a $250 \mathrm{~mL}$ Erlenmeyer flask; add $1 \mathrm{~mL}$ of $1: 1$ sulfuric acid and $0.1 \mathrm{~g}$ sulfamic acid crystals. A $1 \mathrm{~mL}$ portion of a starch indicator solution was added and titration was conducted with a standard $0.002 \mathrm{M} \mathrm{KI} / \mathrm{KIO}_{3}$ solution $\left(0.4458 \mathrm{~g} \mathrm{KIO}_{3}+\right.$ 
$4.35 \mathrm{~g} \mathrm{KI}+310 \mathrm{mg} \mathrm{NaHCO} 3$ in $1 \mathrm{~L} \mathrm{bi-distilled} \mathrm{water).} \mathrm{The} \mathrm{end} \mathrm{point} \mathrm{was} \mathrm{signaled} \mathrm{by} \mathrm{the} \mathrm{dark} \mathrm{purple}$ color due to interaction of the first excess of iodine with starch; $1.00 \mathrm{~mL}$ of the titrant $\equiv 500 \mu \mathrm{g}$ sulfite.

\section{Conclusions}

Sulfite additives in real beverage samples are determined using a simple novel potentiometric sensor based on the use of cobalt phthalocyanine (CoPC) ionophore. The sensor consists of poly (vinyl chloride) membrane containing $\mathrm{CoPC} / \mathrm{TDMAC}^{+} / \mathrm{o}-\mathrm{NPOE}$ as an ion recognition sensing material. The method covers the range $1.0 \times 10^{-6}$ to $2.2 \times 10^{-3} \mathrm{M}(0.08-176 \mu \mathrm{g} / \mathrm{mL})$ with a low detection limit of $1.0 \times 10^{-6} \mathrm{M}(0.08 \mu \mathrm{g} / \mathrm{mL})$, and good selectivity over many other common anions. The performance characteristics of the sensor are validated and proved to be suitable for spectrophotometric covers the linear range 16 to $80 \mu \mathrm{g} / \mathrm{mL}$. Both methods are used for determination of sulfite in real beverages. The results show good correlation with the standard iodometric method. The proposed method offers many advantages over many of those previously described it needs no prior treatment of the sulfite sample, it has a fast response and is cost-effective, and uses simple equipment.

Author Contributions: The listed authors contributed to this work as described in the following: H.S.M.A.-R., S.S.M.H. and A.H.K. gave the concepts of the work, interpretation of the results, the experimental part and prepared the manuscript, A.H.K., S.S.M.H. and A.E.-G.E.A. cooperated in the preparation of the manuscript and A.H.K. and S.S.M.H. performed the revision before submission. A.E.-G.E.A., M.A.A.-O. and E.A.E. revealed the financial support for the work. All authors have read and agreed to the published version of the manuscript.

Funding: This research was funded by King Saud University, through Research Group Project "RGP-1435-047".

Acknowledgments: The authors are grateful to the Deanship of Scientific Research, King Saud University for funding this work through Research Group Project "RGP-1435-047". The authors extend their appreciation to the Deanship of Scientific Research at King Khalid University, Abha, Saudi Arabia for funding this work through General Research Project under grant number (G.R.P-120-41).

Conflicts of Interest: The authors declare no conflicts of interest.

\section{References}

1. Gunnison, A.F. Sulphite toxicity: A critical review of in vitro and in vivo data. Food Cosmet. Toxicol. 1981, 19, 666-682. [CrossRef]

2. Taylor, S.L.; Bush, R.K. Sulfites as food ingredients. Food Technol. 1986, 6, 47-52.

3. Walker, R. Sulphiting agents in foods: Some risk/benefit considerations. Food Addit. Contam. 1985, 2, 5-24. [CrossRef]

4. Smith, V.J. Determination of sulfite using a sulfite oxidase enzyme electrode. Anal. Chem. 1987, 59, 2256-2259. [CrossRef]

5. Langdon, T.T. Preventing of browning in fresh prepared potatoes without the use of sulfiting agents. Food Technol. 1987, 5, 64-67.

6. Yongjie, L.; Li, Y.; Zhao, M. Simple methods for rapid determination of sulfite in food products. Food Control 2006, 17, 975-980.

7. Geetha, K.; Balasubramania, N. An indirect method for the determination of sulfur dioxide using Methyl Red. Microchem. J. 2000, 65, 45-49. [CrossRef]

8. Hassan, S.S.M.; Hamza, M.S.; Mohamed, A.H.K. A novel spectrophotometric method for batch and flow injection determination of sulfite in beverages. Anal. Chim. Acta 2006, 570, 232-239. [CrossRef]

9. Zhan, X.; Dong-hui, L.; Hong, Z. Jin-gou, X. Fluorimetric determination of sulfite by the co-quenching effect of formaldehyde and sulfite on the fluorescence of tetra-substituted amino aluminum phthalocyanine. Anal. Chim. Acta 2001, 448, 71-77.

10. Yang, X.; Guo, X.; Zhao, Y. Novel spectrofluorimetric method for the determination of sulfite with rhodamine B hydrazide in a micellar medium. Anal. Chim. Acta 2002, 456, 121-128. [CrossRef]

11. Fujii, S.; Tokuyama, T.; Abo, M.; Okuba, A. Fluorometric determination of sulfite and nitrite in aqueous samples using a novel detection unit of a microfluidic device. Anal. Sci. 2004, 20, 209-212. [CrossRef] [PubMed] 
12. Jabbari, A.; Shamsipur, M. Kinetic Spectrophotometric Determination of Traces of Sulfite Based on Its Additional Reaction with Methyl Green. Microchem. J. 1993, 48, 349-355. [CrossRef]

13. Afkhami, A.; Sarlak, N.; Zarei, A.R.; Madrakian, T. Simultaneous Kinetic Spectrophotometric Determination of Sulfite and Sulfide Using Partial Least Squares (PLS) Regression. Bull. Korean Chem. Soc. 2006, 27, 863-868.

14. Yamada, M.; Nakada, M.; Suzuki, S. The determination of sulfite in a flow injection system with chemiluminescence detection. Anal. Chim. Acta 1983, 147, 401-404. [CrossRef]

15. Huang, Y.L.; Kim, J.M.; Schmid, R.D. Determination of sulphite in wine through flow-injection analysis based on the suppression of luminol chemiluminescence. Anal. Chim. Acta 1992, 266, 317-323. [CrossRef]

16. Qin, W.; Zhang, Z.; Zhang, C. Reagentless chemiluminescence flow sensor for sulfite. Anal. Chim. Acta 1998, 361, 201-203. [CrossRef]

17. Papkovsky, D.; Uskova, M.A.; Ponomarve, G.V.; Korpela, T.; Kulmale, S.; Guilbault, G.G. Optical sensing of sulfite with a phosphorescent probe. Anal. Chim. Acta 1998, 374, 1-9. [CrossRef]

18. Yoshikawa, K.; Uekusa, Y.; Sakuragawa, A. Determination of sulphite in wines using suppressed ion chromatography. Food Chem. 2015, 174, 387-391. [CrossRef]

19. Aberi, A.; Coelhan, M. Determination of sulfur dioxide in wine using headspace gas chromatography and electron capture detection. Food Add. Contam. A 2013, 30, 226-233. [CrossRef] [PubMed]

20. Rethmeier, J.; Robenstein, A.; Langer, M.; Fischer, U. Detection of traces of oxidized and reduced sulfur compounds in small samples by combination of different high-performance liquid chromatography methods. J. Chromatog. A 1997, 760, 295-302. [CrossRef]

21. Abrahamsson, V.; Hoff, S.; Nielsen, N.J.; Lund, M.N.; Andersen, M.L. Determination of sulfite in beer based on fluorescent derivatives and liquid chromatographic separation. J. Am. Soc. Brew. Chem. 2012, 70, $296-302$. [CrossRef]

22. Masár, M.; Danková, M.; Ölvecká, E.; Stachurová, A.; Kaniansky, D.; Stanislawski, B. Determination of free sulfite in wine by zone electrophoresis with isotachophoresis sample pretreatment on a column-coupling chip. J. Chromatog. 2004, 1026, 31-39.

23. Kim, H.J. Determination of sulfite in foods and beverages by ion exclusion chromatography with electrochemical detection: Collaborative study. J. Assoc. Off. Anal. Chem. 1990, 73, 216-222. [CrossRef] [PubMed]

24. Rawal, R.; Chawla, S.; Pundir, C.S. An electrochemical sulfite biosensor based on gold coated magnetic nanoparticles modified gold electrode. Biosens. Bioelectron. 2012, 31, 144-150. [CrossRef] [PubMed]

25. Campanella, L.; Cipriani, P.; Martini, T.M.; Sammartino, M.P.; Tomasetti, M. New enzyme sensor for sulfite analysis in sea and river water samples. Anal. Chim Acta 1995, 305, 32-41. [CrossRef]

26. Abass, A.K.; Hart, J.P.; Cowell, D. Development of an amperometric sulfite biosensor based on sulfite oxidase with cytochrome c, as electron acceptor, and a screen-printed transducer. Sens. Actuators 2000, 62, 148-153. [CrossRef]

27. Pisoschi, A.M.; Pop, A. Comparative sulfite assay by voltammetry using Pt electrodes, photometry and titrimetry: Application to cider, vinegar and sugar analysis. Open Chem. 2018, 16, 1248-1256. [CrossRef]

28. Norouzi, B.; Parsa, Z. Determination of Sulfite in Real Sample by an Electrochemical Sensor Based on Ni/Poly (4-Aminobenzoic Acid)/Sodium Dodecylsulfate/Carbon Paste Electrode. Russ. J. Electrochem. 2018, 54, 613-622. [CrossRef]

29. Silva, E.M.; Takeuchi, R.M.; Santos, A.L. Carbon nanotubes for voltammetric determination of sulphite in some beverages. Food Chem. 2015, 173, 763-769. [CrossRef]

30. Molinero-Abad, B.; Alonso-Lomillo, M.A.; Dominguez-Renedo, O.; Arcos-Martinez, M.J. Amperometric determination of sulfite using screen-printed electrodes modified with metallic nanoparticles. Mikrochim. Acta. 2013, 180, 1351-1355. [CrossRef]

31. Isaac, A.; Livingstone, C.; Wain, A.J.; Compton, R.G.; Davis, J. Electroanalytical methods for the determination of sulfite in food and beverages. TrAc-Trends Anal. Chem. 2006, 25, 589-598. [CrossRef]

32. Kamel, A.H.; Hassan, A.M.E. Solid Contact Potentiometric Sensors Based on Host-Tailored Molecularly Imprinted Polymers for Creatine Assessment. Int. J. Electrochem. Sci. 2016, 11, 8938-8949. [CrossRef]

33. El-Naby, E.H.; Kamel, A.H. Potential transducers based man-tailored biomimetic sensors for selective recognition of dextromethorphan as an antitussive drug. Mater. Sci. Eng. C 2015, 54, 217-224. [CrossRef] [PubMed] 
34. El-Kosasy, A.; Kamel, A.H.; Hussin, L.; Ayad, M.F.; Fares, N. Mimicking new receptors based on molecular imprinting and their application to potentiometric assessment of 2, 4-dichlorophenol as a food Taint. Food Chem. 2018, 250, 188-196. [CrossRef] [PubMed]

35. Kamel, A.H.; Jiang, X.; Li, P.; Liang, R. A paper-based potentiometric sensing platform based on molecularly imprinted nanobeads for determination of bisphenol A. Anal. Methods 2018, 10, 3890-3895. [CrossRef]

36. Kamel, A.H.; Soror, T.Y.; Al-Romian, F.M. Graphite Solid-Contact Mepiquat Potentiometric Sensors Based on Molecularly Imprinted Polymers and Their Application to Flow Through Analysis. Anal. Meth. 2012, 4, 3007-3012. [CrossRef]

37. Hassan, S.S.M.; Badr, I.H.A.; Kamel, A.H.; Mohamed, M.S. A Novel Poly (Vinyl Chloride) Matrix Membrane Sensor for Batch and Flow-injection Determination of Thiocyanate, Cyanide and Some Metal Ions. Anal. Sci. 2009, 25, 911-917. [CrossRef]

38. Badr, I.H.A.; Meyerhoff, M.E.; Hassan, S.S.M. Novel response mechanism and application of sulfite sensitive polymeric membrane electrode based on dithiocarbamate complexes of mercury(II). Anal. Chim. Acta 1995, 310, 211-221. [CrossRef]

39. Hutchins, R.S.; Molina, P.; Alajarín, M.; Vidal, A.; Bachas, L.G. Use of a guanidinium ionophore in a hydrogen sulfite-selective electrode. Anal. Chem. 1994, 66, 3188-3192. [CrossRef]

40. Hassan, S.S.M.; Marei, S.A.; Badr, I.H.; Arida, H.A. Flow injection analysis of sulfite ion with a potentiometric titanium phosphate-epoxy based membrane sensor. Talanta 2001, 54, 773-782. [CrossRef]

41. Zagal, J.H. Metallophthalocyanines as catalysts in electrochemical reactions. Coord. Chem. Rev. 1992, 119, 89-136. [CrossRef]

42. Thamae, M.; Nyokong, T. Interaction of sulfur dioxide and cyanide with cobalt(II) tetrasulfophthalocyanine in aqueous media. Polyhedron 2002, 21, 133-140. [CrossRef]

43. IUPAC. Analytical Chemistry Division Commission on Analytical Nomenclature. Pure Appl. Chem. 2000, 72, 185.

44. FDA. Guidance for Industry: Analytical Procedures and Method Validation, Chemistry, Manufacturing, and Controls Documentation; U.S. Department of Health and Human Services: Washington, DC, USA, 2015 July.

45. Montgomery, D.C. Introduction to Statistical Quality Control, 6th ed.; John Wiley \& Sons, Inc.: Hoboken, NJ, USA, 2009.

46. IUPAC. Analytical Chemistry Division, Commission on Analytical Nomenclature, Recommendations forNomenclature of Ion-Selective Electrodes. Pure Appl. Chem. 1976, 48, 127-132. [CrossRef]

47. American Public Health Association. Standard Methods for the Examination of Waters and Wastewaters, 23th ed.; American Public Health Association: Baltimore, Maryland, 2017.

48. Hassan, S.S.M.; El-Nashar, R.M.; El-Tantawy, A.S.M. A new validated potentiometric method for batch and continuous quality control monitoring of oseltamivir phosphate (Taminil) in drug formulations and biological fluids. Electroanalysis 2013, 25, 408-416. [CrossRef]

Sample Availability: Samples of the compounds are available from the authors.

(C) 2020 by the authors. Licensee MDPI, Basel, Switzerland. This article is an open access article distributed under the terms and conditions of the Creative Commons Attribution (CC BY) license (http://creativecommons.org/licenses/by/4.0/). 